\title{
Anasarca, steatorrhea, and hypoalbuminemia 18 years after total gastrectomy: a case report
}

\author{
Yu Igata* (D), So Okubo, Yu Ohkura, Masaki Ueno and Harushi Udagawa
}

\begin{abstract}
Background: Pancreatic exocrine insufficiency (PEI) is known to occur after total gastrectomy. We experienced a case of PEI occurring 18 years after surgery, leading to a potentially fatal condition of capillary leak syndrome (CLS).

Case presentation: The case is a 58-year-old man on a healthy diet who underwent total gastrectomy 18 years before. He was admitted for a 3-month history of anasarca, steatorrhea, and hypoalbuminemia. An episode of fever occurred during workup, followed by pulmonary edema and shock. The patient was transferred to the intensive care unit and was started on fluid management with albumin infusion. A multidisciplinary team meeting was held, and a clinical diagnosis of PEI resulted in CLS was made and we started administration of oral pancrelipase to show clinical improvement. The patient was discharged, and he remained asymptomatic for 13 months.

Conclusion: In a post-gastrectomy patient with malnutrition, PEl should be suspected regardless of the period since surgery. When recognized, immediate replenishment of albumin and pancreatic enzymes should be initiated to prevent clinical deterioration.
\end{abstract}

Keywords: Total gastrectomy, Anasarca, Hypoalbuminemia, Pancreatic exocrine insufficiency, Capillary leak syndrome, Pancrelipase

\section{Background}

Pancreatic exocrine insufficiency (PEI) is known to occur after total gastrectomy, and it commonly manifests as steatorrhea, malnutrition, and weight loss [1]. However, diagnosis of a patient presenting with anasarca, steatorrhea, and hypoalbuminemia 18 years after total gastrectomy is challenging. We experienced a case of unrecognized PEI which resulted in pulmonary edema and shock, constituting capillary leak syndrome (CLS), a constellation of disease manifestations associated with increased capillary permeability [2]. The patient was successfully treated with fluid management and administration of oral pancrelipase, a porcine pancreatic extract containing lipases, proteases, and amylases.

\section{Case presentation}

A 58-year-old man with a history of an advanced gastric cancer treated by total gastrectomy and splenectomy

\footnotetext{
* Correspondence: igata-nms@umin.org

Department of Gastroenterological Surgery, Toranomon Hospital, 2-2-2

Toranomon, Minato-ku, Tokyo 105-8470, Japan
}

and Roux-en-Y reconstruction with D2 lymph node dissection 18 years before was admitted with a 3-month history of anasarca, steatorrhea, and hypoalbuminemia. He had been taking vitamin supplementations and had been followed up annually for his gastric cancer with no signs of recurrence. He had a medical history of stroke 3 years before. As for social history, he drank up to 300 $\mathrm{g}$ of alcohol a day until 42 years old, and thereafter, he cut down to $80 \mathrm{~g}$ of alcohol a week. He was on a regular diet, and he was never diabetic. On presentation, his serum albumin was $1.2 \mathrm{~g} / \mathrm{dl}$ (reference range $4.1-5.1 \mathrm{~g} /$ $\mathrm{dl}$ ), vitamin $\mathrm{B}_{12}$ was $1410 \mathrm{ng} / \mathrm{L}$ (233-914 ng/L), and folic acid was $5.8 \mu \mathrm{g} / \mathrm{L}(3.6-12.9 \mu \mathrm{g} / \mathrm{L})$ (Table 1$)$. Computed tomography showed pleural effusions and ascites. Thorough examinations were scheduled, where he developed fever, bilateral pulmonary edema, and shock (Fig. 1). The patient was transferred to the intensive care unit and was started on immediate albumin resuscitation. As the blood cultures were negative, this "sepsis-like" syndrome with hypoalbuminemia, anasarca, pulmonary edema, and shock was consistent with the clinical 
Table 1 Laboratory data on admission

\begin{tabular}{|c|c|c|c|c|c|}
\hline \multicolumn{6}{|c|}{ Laboratory data } \\
\hline WBC & 9200 & $/ \mu l$ & $\mathrm{Na}$ & 138 & $\mathrm{mEq} / \mathrm{l}$ \\
\hline RBC & $249 \times 10^{4}$ & $/ \mu l$ & K & 4.0 & $\mathrm{mEq} / \mathrm{l}$ \\
\hline $\mathrm{Hgb}$ & 8.9 & $\mathrm{~g} / \mathrm{dl}$ & $\mathrm{Cl}$ & 108 & $\mathrm{mEq} / \mathrm{l}$ \\
\hline $\mathrm{Hct}$ & 25.9 & $\%$ & $\mathrm{Ca}$ & 7.3 & $\mathrm{mg} / \mathrm{dl}$ \\
\hline \multirow[t]{2}{*}{ PLT } & $37.4 \times 10^{4}$ & $/ \mu l$ & Glucose & 78 & $\mathrm{mg} / \mathrm{dl}$ \\
\hline & & & $\mathrm{HbA1c}$ & 3.4 & $\%$ \\
\hline РТ\% & 58.0 & $\%$ & & & \\
\hline \multirow[t]{2}{*}{ APTT } & 34.2 & Sec & CEA & 17.0 & $\mu \mathrm{g} / \mathrm{l}$ \\
\hline & & & CA19-9 & 47 & $\mathrm{U} / \mathrm{ml}$ \\
\hline $\mathrm{TP}$ & 4.5 & $\mathrm{~g} / \mathrm{dl}$ & DUPAN-2 & 276 & $\mathrm{U} / \mathrm{ml}$ \\
\hline Alb & 1.2 & $\mathrm{~g} / \mathrm{dl}$ & Span-1 & 45.0 & $\mathrm{U} / \mathrm{ml}$ \\
\hline AST & 33 & IU/I & SIL-2R & 563 & $\mathrm{U} / \mathrm{ml}$ \\
\hline ALT & 36 & IU/I & & & \\
\hline LD & 329 & IU/I & Vitamin $B_{12}$ & 1410 & $\mathrm{ng} / \mathrm{l}$ \\
\hline$\gamma$-GTP & 18 & IU/I & Folic acid & 5.8 & $\mu g / l$ \\
\hline ALP & 234 & IU/I & $\mathrm{Zn}$ & 27 & $\mu \mathrm{g} / \mathrm{dl}$ \\
\hline AMY & 30 & IU/I & & & \\
\hline CK & 147 & IU/I & & & \\
\hline BUN & 20 & $\mathrm{mg} / \mathrm{dl}$ & & & \\
\hline Cre & 0.87 & $\mathrm{mg} / \mathrm{dl}$ & & & \\
\hline T-bil & 0.7 & $\mathrm{mg} / \mathrm{dl}$ & & & \\
\hline CRP & 2.0 & $\mathrm{mg} / \mathrm{dl}$ & & & \\
\hline
\end{tabular}

diagnosis of CLS. Due to the rapid clinical deterioration from an undiagnosed etiology, a multidisciplinary team meeting was held. From the results of the multiple examinations (Table 2), a diagnosis of PEI was suspected, and an oral daily dose of $1800 \mathrm{mg}$ of pancrelipase was initiated (Fig. 2). The patient gradually improved and the clinical signs of CLS resolved (Fig. 3). The patient was discharged and is routinely followed up, remaining asymptomatic for 13 months.

\section{Discussion}

Pancreatic exocrine insufficiency presenting with anasarca 18 years after total gastrectomy, associated with a potentially fatal course of CLS, has not been reported in the previous literatures.

Although PEI after total gastrectomy is a welldocumented complication [1,3-5], there is a paucity of publication focused on the timing of the onset of malnutrition-associated symptoms after gastrectomy. Therefore, suspecting a relatively late onset of PEI in this rare clinical setting was a challenge, which leads to a diagnostic delay. From the examination results, the malnutrition state could not be attributed to malignancy, infection, autoimmune diseases, amyloidosis, nephrotic syndrome, liver failure, Crohn's disease, Celiac disease, and other causes of hypoalbuminemia, which lead to a clinical diagnosis of PEI. Furthermore, the fact that the patient is remaining asymptomatic on pancrelipase supports PEI as the underlying etiology.

This is also the first report on untreated PEI resulting in bilateral pulmonary edema and shock leading to the diagnosis of CLS. Capillary leak syndrome has been used

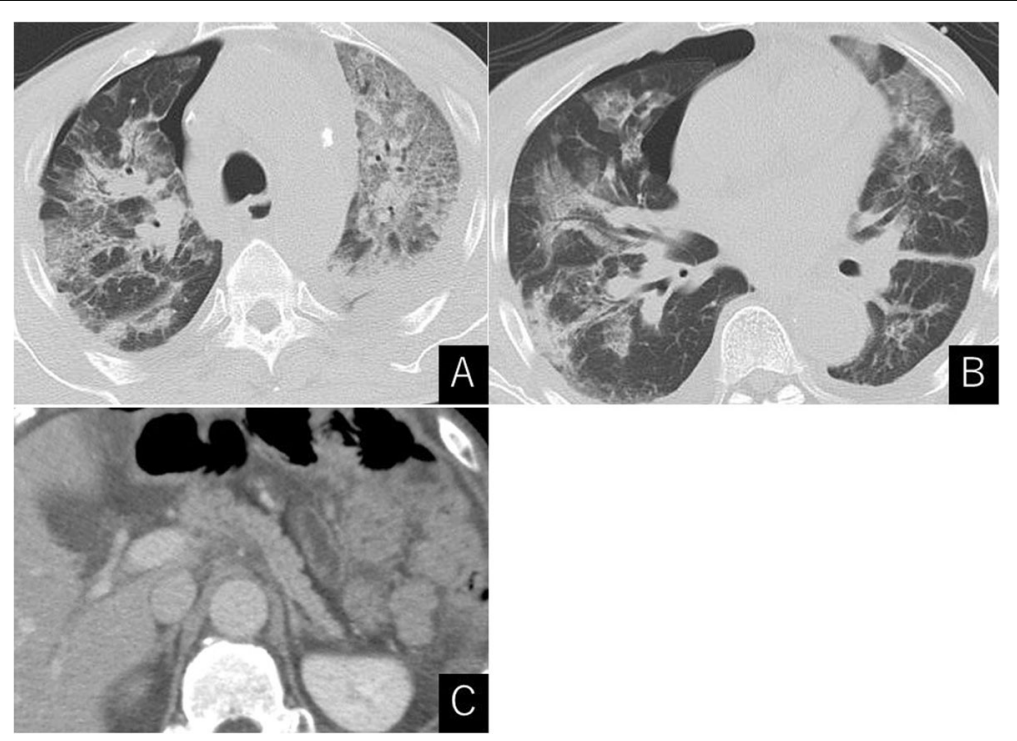

Fig. 1 CT scan showed severe bilateral pulmonary edema. Small amount of iatrogenic pneumothorax was secondary to thoracentesis (a, $\mathbf{b})$. Pancreas was intact (c) 
Table 2 Results of core examinations performed

\begin{tabular}{ll}
\hline Performed examinations & Brief findings \\
\hline Contrast enhanced CT & $\begin{array}{l}\text { Fatty liver. No } \\
\text { tumors detected }\end{array}$ \\
MRI & No tumors detected \\
Endoscopic ultrasonography & No tumors detected \\
Colonoscopy & Floating oil droplets \\
& were evident (Fig. 2) \\
Small intestine endoscopy & No evidence \\
& of Crohn's \\
Albumin scintigraphy & lymphangiectasia \\
& No evidence of \\
Rectal biopsy & albumin loss \\
Bone marrow biopsy & No amyloid deposits \\
& No evidence \\
& of lymphoma \\
\hline
\end{tabular}

CT computed tomography, MRI magnetic resonance imaging to describe this rare constellation of disease manifestations associated with increased vascular permeability to proteins, i.e., edema, cavity effusions, non-cardiac pulmonary edema, and hypotension. It is divided into two categories, idiopathic or secondary, based on the underlying diseases [2]. The relationship between PEI and CLS is unclear, but the condition of PEI could have played a role in developing CLS. Therefore, we hypothesized that by recognizing PEI and initiating treatment with pancrelipase and albumin infusion as needed, progression to CLS could be prevented.

As alteration of normal anatomy and pancreatic denervation is reported to be responsible for PEI, patients operated on the esophagus, duodenum, and pancreas are also at risk for developing maldigestion $[3,4]$. In patients with malnutrition-associated symptoms with histories of upper gastrointestinal surgery, PEI should be sought

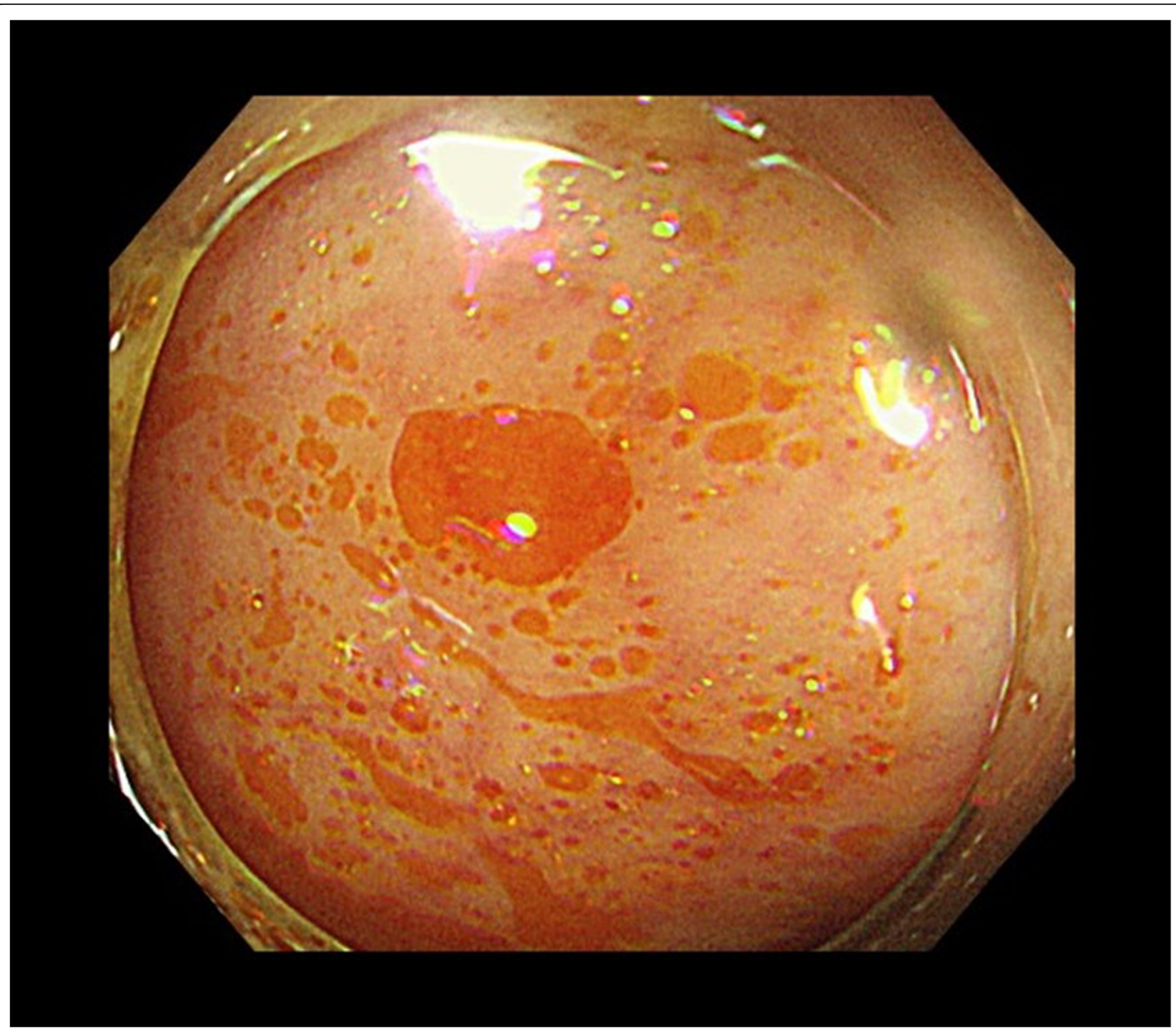

Fig. 2 Colonoscopy showed prominent oil droplets 


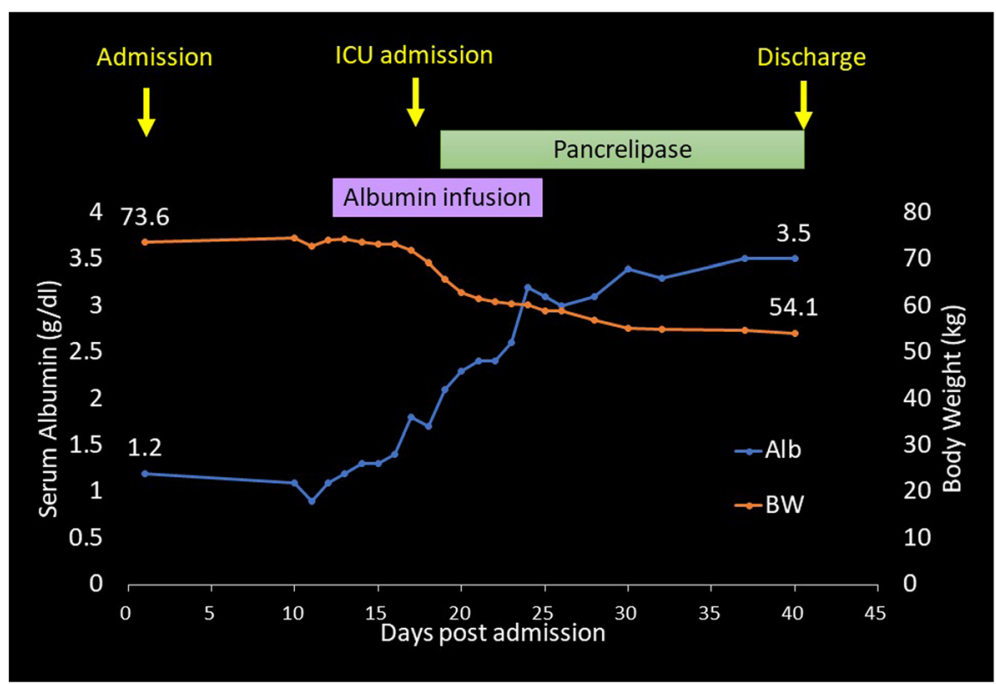

Fig. 3 Clinical course with transitional changes in the serum albumin level and body weight

regardless of time from surgery. Although previous reports on the efficacy of pancreatic enzyme replacement therapy have been controversial [5], given the profound severe consequences, administering pancrelipase in this patient population is thought to be acceptable.

\section{Conclusions}

Pancreatic exocrine insufficiency can occur 18 years after total gastrectomy and can present with anasarca. Untreated PEI harbors risks of developing a potentially fatal clinical condition of CLS. Surgeons must suspect PEI and initiate albumin and pancrelipase replenishment as needed without hesitation.

\section{Abbreviations}

CLS: Capillary leak syndrome; CT: Computed tomography; MRI: Magnetic resonance imaging; PEl: Pancreatic exocrine insufficiency

\section{Acknowledgements}

None

\section{Declaration}

None declared

\section{Authors' contributions}

$\mathrm{YI}, \mathrm{SO}$, and $\mathrm{YO}$ examined and managed the patient, wrote the manuscript, and revised it critically for important intellectual content. MU and HU gave final approval for the content. All authors read and approved the final manuscript.

\section{Funding}

None.

\section{Availability of data and materials}

The dataset supporting the conclusions of this article is included within the article.

\section{Ethics approval and consent to participate}

Not applicable as a case report is not regarded as a study according to the "Ethical Guidelines for Medical and Health Research Involving Human

Subjects" of the Japanese Ministry of Health, Labour and Welfare.

\section{Consent for publication}

Written informed consent was obtained from the patient for publication of this case report, including their medical data and images.

\section{Competing interests}

The authors declare that they have no competing interests.

Received: 2 September 2019 Accepted: 27 September 2019 Published online: 24 October 2019

\section{References}

1. Straatman J, Wiegel J, van der Wielen N, Jansma EP, Cuesta MA, van der Peet DL. Systematic review of exocrine pancreatic insufficiency after gastrectomy for cancer. Dig Surg. 2017;34(5):364-70

2. Siddall $\mathrm{E}$, Khatri $\mathrm{M}$, Radhakrishnan J. Capillary leak syndrome: etiologies, pathophysiology, and management. Kidney Int. 2017;92(1):37-46.

3. Singh VK, Haupt ME, Geller DE, Hall JA, Quintana Diez PM. Less common etiologies of exocrine pancreatic insufficiency. World J Gastroenterol. 2017; 23(39):7059-76.

4. Dominguez-Munoz JE. Pancreatic enzyme replacement therapy: exocrine pancreatic insufficiency after gastrointestinal surgery. HPB. 2009;11(Suppl 3):3-6.

5. Antonini F, Crippa S, Falconi M, Macarri G, Pezzilli R. Pancreatic enzyme replacement therapy after gastric resection: an update. Dig Liver Dis. 2018 50(1):1-5.

\section{Publisher's Note}

Springer Nature remains neutral with regard to jurisdictional claims in published maps and institutional affiliations. 